\title{
CLIMATIC ATMOSPHERIC HEAT AND MOISTURE FLUXES OF EURASIA DUE TO OCEAN CLIMATE PROCESSES
}

\author{
Alexei Kartushinsky ${ }^{1,2}$ \\ ${ }^{1}$ Siberian Federal University, Krasnoyarsk, Russia \\ ${ }^{2}$ Institute of Biophysics SB RAS, Krasnoyarsk, Russia
}

\begin{abstract}
The sea-air interactions in the troposphere give rise in changes in direction of heat and moisture fluxes due to different atmospheric pressure. The paper discusses the possibility of using the gradient method for processing satellite data to study the spatial and temporal scales of climatic and synoptic variability of dynamic processes of the atmosphere and ocean. Recent software was used for applying and analyzing satellite and contact data. The information technology has been implemented to analyze weather and climatic conditions in Eurasia using computer processing of long-term observation series of meteorological and oceanological parameters. Based on the methods of mathematical statistics, correlations in terms of surface temperature between dynamically active zones of the World Ocean have been determined. With the dynamics of the frontal zone of the Gulf Stream as an example, the problem of the influence of the structural features of the gradient field of the ocean temperature on local changes in the weather and climatic conditions of the land is discussed. The results obtained suggest that the regional features of the dynamics of the hydrological frontal Atlantic systems are derived from the geostrophic circulation in Eurasia.
\end{abstract}

\section{Introduction}

The ocean and the atmosphere are two self-organizing thermodynamic systems that, by their interaction, provide the climatic and weather regimes of the Earth's planetary troposphere. Short-term energy interaction occurs between the near-surface layer of the atmosphere and the surface layer of the ocean, forming large-scale (mesoscale) circulation in the upper atmosphere and lower layers of the ocean due to vertical flows of heat, moisture, salt and density stability.

The main mechanism of acceleration (or deceleration) of horizontal flows is the coaction of the force of the pressure gradient, the deflecting force of the Earth's rotation. Also, the friction force at the boundaries of the sea-air layers for transfer (or absorption) of

\footnotetext{
*Corresponding author: kartushka@mail.ru
} 
kinetic turbulent energy is important. Jet streams in the ocean and stable hydrological fronts are thus formed, including the formation of mesoscale eddies [1].

It is well known for everyone that circulation flows in the troposphere forms areas of high (anticyclones) and low (cyclones) atmospheric pressure and atmospheric fronts with different accumulation quantity moister (precipitation) and temperature [2]. However, longterm weather forecasts are still not accurate enough due to sea temperature anomalies, especially in the surface layer of the ocean [3].

The study of the interaction of processes in the ocean and the atmosphere with the determination of the degree of climate and weather variability on terrestrial land is important feature for future scientific knowledge about Global Climate Changes.

\section{Materials and methods}

As the initial data, the work uses satellite data of the sea surface temperature (SST) of the ocean, measured for different periods of time by hardware with high and low spatial resolution (AVHRR MCSST, CZCS, SeaWIFS, MIRAS, AQUARIUS, MODIS, MSS: for choice 1982-2015). Also, meteorological data on observation Eurasian stations with different time periods of averaging was used. The processing and analysis of data from satellite and contact measurements were done using modern information technology and software tools. The software for the calculation of the sea surface gradient characteristics $[4,5]$ and a software application for analysis of weather and climatic variability were used [6].

\section{Results and discussion}

To determine the global climatic regime of the ocean, the cross-correlation of the temperature gradients averaged over time and space for the different area of the World Ocean identified by the dynamic activity of the frontal hydrological zones was calculated. The results are presented in Figure 1 from which features of the ocean global heat dynamic transfer, called the Conveyer Belt [7], are visible.

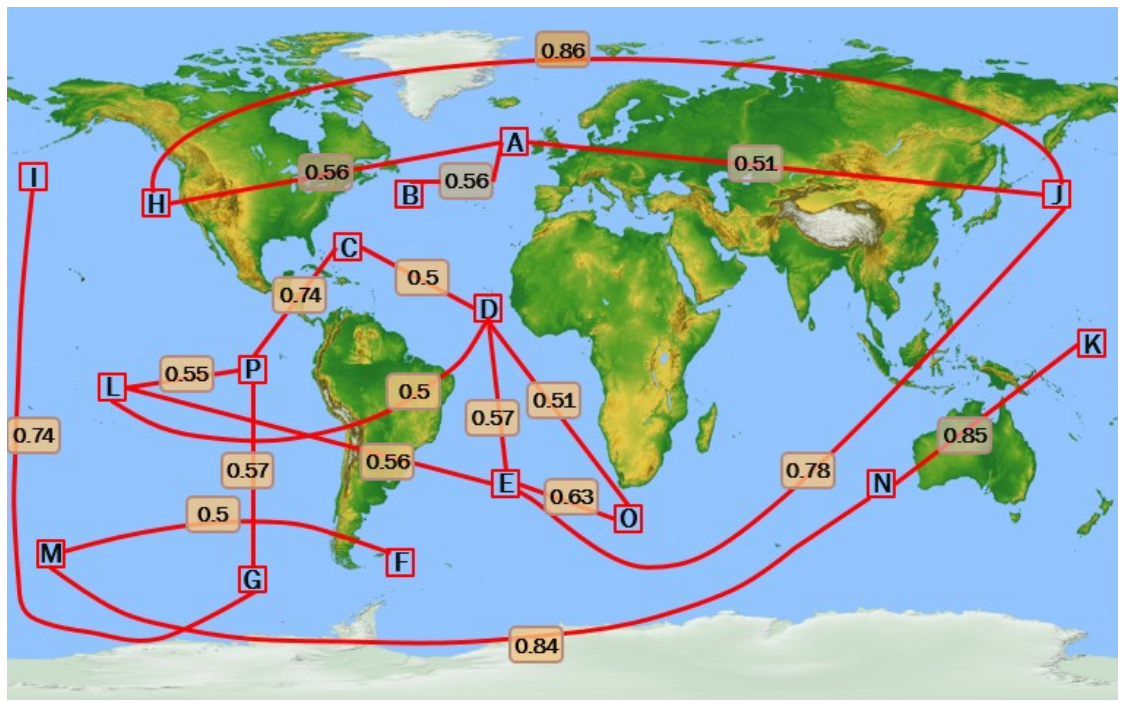

Fig. 1. Cross-correlations between sectors (dynamically active zones) on the mean average annual gradients of sea surface temperature (1982-2000). 
To calculate SST gradients, we used software for the statistics of the gradient fields of the surface temperature for mean year averaging periods of time in the different ocean regions. We calculated the correlation coefficients for different zones of the World Ocean (Figure 1), which we designated by squares (letters) and the correlation coefficient (numerical).

In order to substantiate the description of the influence of regional oceanic processes formed by jet streams, the interaction zone of the Gulf Stream (warm water) and the North Labrador current (cold water) was chosen as an example (Figure 2). The structure and spatial position of this frontal zone is a trigger for regulating the flows of heat and humidity in the atmosphere and the influence of the ocean on the weather conditions of Eurasia. It is necessary to pay attention to the spatial scales of the size of frontal zone for different seasons, such as summer and winter.

Naturally, the spatial scales of the transfer of warm waters from the Gulf of Mexico to the shores of western Europe are determined by the severity of winter and the state of the ice cover. However, meandering of the Gulf Stream can reduce the flow velocity and blur the boundaries of the frontal zone, which will impede the flow of heat to the shores of Eurasia. Thus, it is necessary to monitor the structure of the gradient temperature field and its spatial scales in order to determine the influence of seasonal fluctuations in the cyclone formation regime due to evaporation in the Icelandic minimum region in the Northern Atlantic (the formation area of the low pressure atmospheric zone).

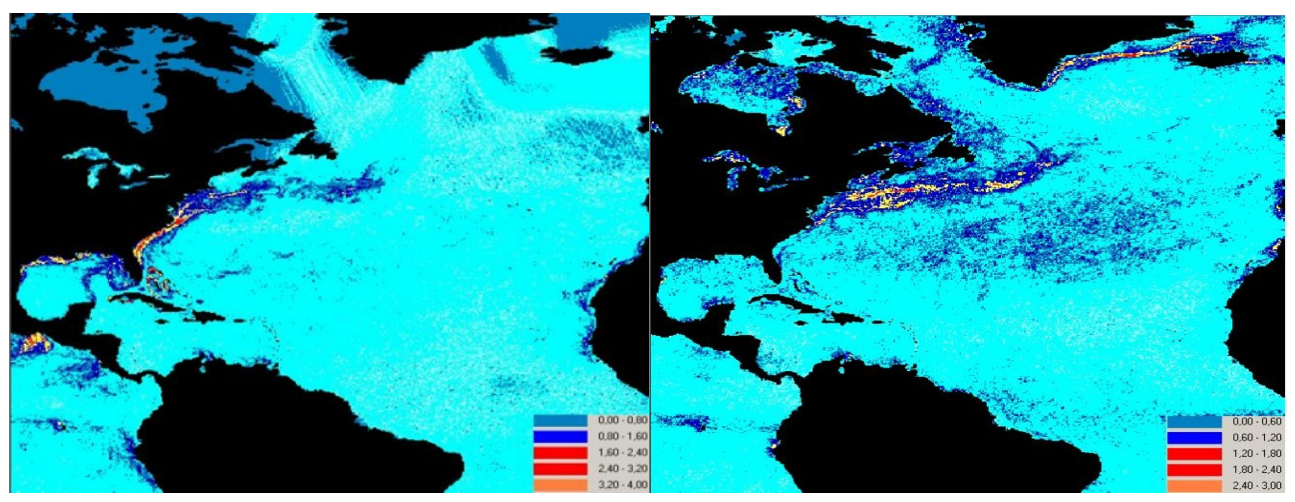

Fig. 2. Local mean seasonal temperature frontal zones of the North Atlantic (Gulf Stream zone); red maximum value of temperature gradient. (left - winter 2000; right - summer 2000).

According to meteorological data in the structure of circulation in the North hemisphere, over the past 15-25 years, there has been a violation of stable latitudinal (zonal) transport and a transition to meridional circulation [8].

For example, the trajectories of the meridional displacement of the lower pressure area, which are commonly called "diving cyclones", moving from northwest to southeast are presented (Figure 3). For the Arctic region, such structural changes in heat and precipitation fluxes can significantly affect the climate and weather changes, which must be assessed by the speed of change of time-space scale of hydrological dynamic processes in the Northern Atlantic.

In order to show the possible influence of the trajectory of diving cyclones on climate change in the Arctic region of Russia, we used the software to create climatograms [6]. Here we use the meteorological mean monthly data of air temperature and precipitation. 

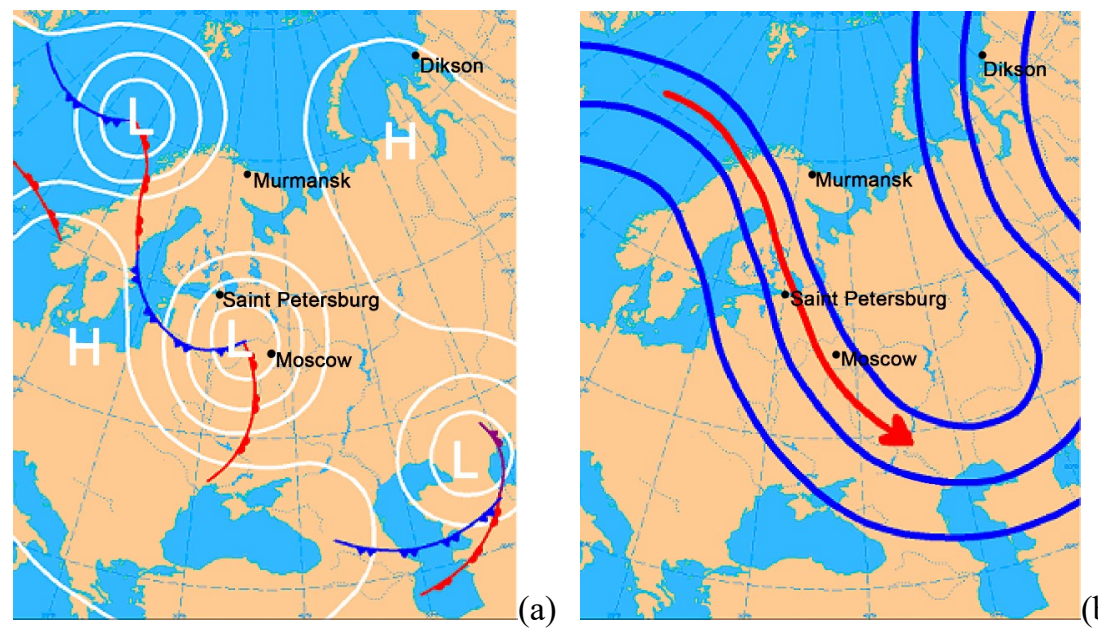

Fig. 3. The meridional trajectory of “diving cyclones” over Eurasia; a) L - area of low pressure; H high pressure area. The warm front is shown in red, cold air is in blue; b) the main trajectory of heat and moisture flow.

For evaluation of the year oscillations in the mean monthly weather condition differences, the climatograms for different time periods of the meteorological station of the Russian Arctic region - Dikson are presented. To emphasize the significance of climate change for the period - the middle of the 20th century and the beginning of the 21 st century, for comparison, we are shown the climatograms for different years $(1966,1970,2018)$. (Fig. 4).
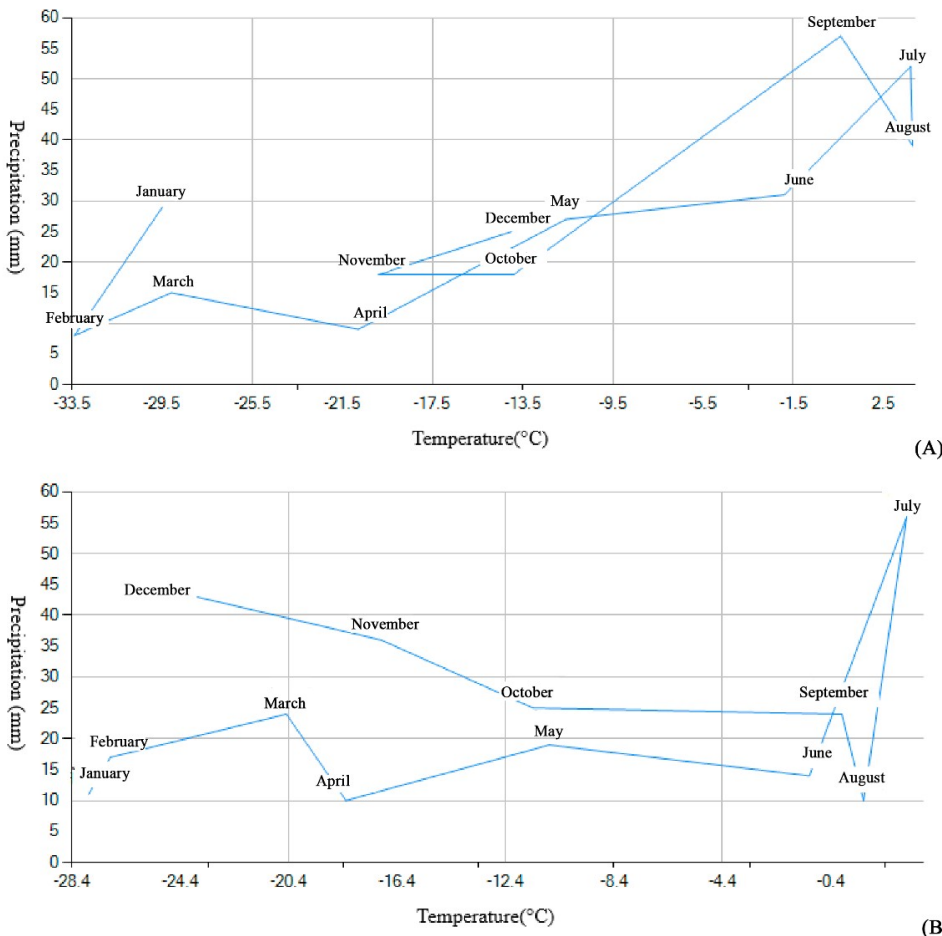


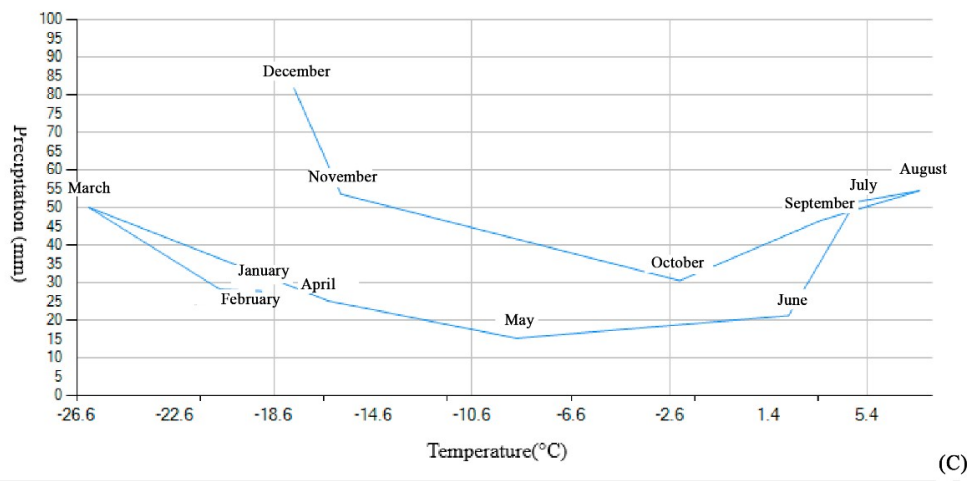

Fig. 4. Climatograms for the Dikson weather station: A - 1966, B - 1970 and C - 2018.

For the analysis of intra-annual changes in mean monthly air temperature and precipitation, climatograms with the most different shapes were selected. Climatograms for the example were selected for the interannual period of 4, 18 and 52 years for comparison with the minimum negative seasonal index of the North Atlantic Oscillations (NAO) in winter and summer (the maximum number of cyclones is 1966 and 1970) and the minimum, but positive NAO (the minimum number of cyclones in 2018) [8]. The NAO shows a direct ocean-atmosphere relationship in the North Atlantic.

For 50-55 years, there has been a shift towards an increase in the average monthly air temperature and an increase in average monthly precipitation (Figure 4C). The physical mechanism of the change in the amount of heat and moisture on the territory of Eurasia in the North Atlantic can be considered a sequence of ocean-atmosphere interaction processes: at the beginning, there is an exacerbation of the average seasonal surface temperature gradients in the frontal zone of the Gulf Stream - Labrador Current. Then there is an increase in the number of cyclones in the Icelandic minimum zone due to an increase in the amount of heat and evaporation. After that, the formed "diving cyclones" along the trajectory of the meridional direction move from the northwest to the southeast. The final stage in the action of the physical mechanism of this process is the pumping of a certain amount of heat and moisture from south to north.

\section{Conclusion}

Based on the results obtained, it can be assumed that the nature of the global warming lies in the background intrasecular range. The main mechanism for regulating weather conditions is the interaction of the ocean and the atmosphere at seasonal layer of variability.

The spatial position of climatic zones according to the ecological characteristic of aridity and humidity must be evaluated by the degree of interaction of the hydrological component of the ocean and the exchange of heat and moisture. The structure and spatial scales of climatic zones must be mapped based on the current state of biomes and ecosystems in terms of moisture and heat transfer regimes not on a local (regional) spatial scale, but along stable trajectories of circulation structures formed by the interaction of the ocean and the atmosphere.

The results obtained suggest that the known regional features in dynamics of the oceanatmosphere climatic systems are derived geostrophic circulation on Eurasia. The calculations of the global ocean surface gradient characteristics based on satellite data allow us to identify areas with different dynamic activity which play a key role in determining a location of zones with a manifestation of sea-air synergism. However, one cannot ignore regional features of dynamics of ocean energy-active zones demonstration and structural 
features of local interaction of processes in separate areas of Global ocean and heat and moisture fluxes in the Earth troposphere.

\section{References}

1. S. Griffies, M. Winton, G.A. Whit et. al., Impacts on ocean heat from transient mesoscale eddies in a hierarchy of climate models. J. of Climate, 28, 3 (2015)

2. J. D. Hanwell, Atmospheric Processes. (1980)

3. C. E. Bulgin, C. J. Merchant, D. Ferreira, Tendencies, variability and persistence of sea surface temperature anomalies. Sci. Rep. (2020)

4. A. Kartushinsky, N. Kukoba, Investigation of gradient fields of the Earth surface based on satellite data. Vestnik SibGAU, 16(3). (2015)

5. N. Ogorodov, A. Kartushinsky, Information technology of satellite data processing for Global Ocean surface gradient characteristics calculation, in CEUR Workshop Proceedings. (2019)

6. A. Kartushinsky, L. Sashko., A. Shevyrnogov, Certificate of state registration of the software. Research of the variability of climatic conditions in the surface layer of the atmosphere. Russia. (2018)

7. J. D. Zika, M. H. England, W. P. Sijp, The ocean circulation in thermohaline coordinates. J. Phys. Oceanogr., 42. (2012)

8. M.G. Lebedeva, A.R. Lupo, Y.G. Chendev, O.V. Krymskaya and A.B. Solovyev, Changes in the Atmospheric Circulation Conditions and Regional Climatic

Characteristics in Two Remote Regions Since the Mid-20th Century. Atmosphere, 10, 11. (2019) 